\title{
Finding Clog Models for the Urban Traffic Blocking \& Assessment of Corridors
}

\author{
Awari Mahesh Babu
}

\begin{abstract}
Urban travel blockage is one of the serious issues which are affecting travelling time. This impact is on economical ability of transportable, non-element of condition, psychosomatic stresses and a movement irregularity on movement. There is a need to indentify clog models for the remarkable impact boil down in peak hour gridlock. The blockage standards can be followed the characteristic located on street with hustle. The clog is created with the overhead conveyed with inconsistent factors and show the way to the fate. These aspects are revealed that they are because of impact of certain trademark impact from elements of land use, street symmetrical, and commute and street organize attributes. This research is encircled on with the staggered distressing variables. GPS information, GIS support tactic is proposed in the assessment for information and a clog model is related to discover clog factors.

The current paper compacts with the deliberate the blockage criterions, and clog produced factors for the Dilsukhnagar zone (Gaddianaram region) Hyderabad, Telangana State, INDIA using Principal Component Analysis (PCA) and regression analysis.
\end{abstract}

Keywords: Clog model; traffic; PCA; land use; blockage; aGIS and aGPS.

\section{INTRODUCTION}

Urbanization is the physical development of urban regions from provincial territories because of populace movement to a current urban zone. Urbanization is determinedly connected to modernization, industrialization, and the sociological system of protection. Fast urbanization causes unpredictable and unplanned development of urban hub which turns out to be progressively mixed-up with the way that it must occur inside the developed region. This influence of incessantly developing populace brings about congestion and ends up weight to limited community progression extravagance which powers the white collar class just as creator to move to remote rural areas, marvel called Urban Sprawl or Growth. Urbanization working in the periphery brings various Transportation issues of wellbeing, clog, mishaps, stopping, the board and requirement. [1]

The analysis is tried, with mention to the symmetrical, commute, effectiveness and land use qualities of the assessment zone, to recognize the significant routes with

Revised Manuscript Received on September 15, 2019.

Dr Awari Mahesh Babu: Professor of Civil Engineering, Nalla Narasimha Reddy Education Society's group of Institutions, Hyderabad. T.S. India traffic attributes as autonomous qualities of risk area as beginning to distinguish the connections without delay.

\section{METHODOLOGY}

\section{PRINCIPAL COMPONENT ANALYSIS}

The major focus of principal component analysis (PCA) is to diminution the magnitude of an informational indicator containing of countless facets, while keeping as far as you can of the variation within the data collection. This can be accomplished by shifting to some other arrangement of variables; the main apparatuses (PCs), that are uncorrelated and that can be structured so the very first few retain the majority of the version present in each one the original factors. [2]

Principal Component Analysis is an entrenched method for dimensionality reduction and multivariate evaluation. Occurrence of its software comprises data requirements, image planning,

representation, procedural data analysis, design recognition, and period immemorial expectancy. PCA compress the multiplicity in related multivariate features to lots of non-corresponded sections, each one of which can be a particular straight mix of the main facets. The split non-corresponded sections are known as Principal Components (PC) and are assessed by the eigenvectors of the covariance system of the very first facets. Afterward, the objective of PCA is to reach stinginess and decrease dimensionality by eliminating the most controlled amount segments that reflect the vast majority of the amount from the principal multivariate info as well as abridge the info together with very little loss of information .

In PCA, the drawing out of PC can be made utilizing either unique multivariate informational index or utilizing the covariance network if the first informational index isn't accessible. In determining PC, the relationship grid might be utilized, rather than the covariance framework, when diverse factors in the informational index are estimated utilizing distinctive units or if diverse factors have diverse fluctuations. Utilizing the relationship network is proportional to institutionalizing the factors to zero mean and unit standard deviation. [3]

Published By: 


\section{Principal component analysis}

The most important notion of important part evaluation (PCA) will be to reduce the dimensionality of an informational group consisting of an expansive variety of interrelated things, while holding

none the less much as might reasonably be due to the number within the informational indicator. This can be accomplished by shifting to some other arrangement of variables, the leading sections (PCs), that can be uncorrelated, and that are asked so the first few hold nearly all the number present in nearly all the initial facets. [4]

The PCA model can be represented by:

$$
U_{m \times 1}=W_{m x d} X_{d x 1}
$$

-andi-..-(i)

Where $u$, an m-dimensional vector, is a projection of $x$

The original, d-dimensional information vector $(m<d)$.

It can be revealed that the $m$ projection vectors that exploit the inconsistency of $U$, called the principal axes, are known by the eigenvectors $\mathrm{e} 1, \mathrm{e} 2, \ldots$, em of the data set's covariance matrix $\mathrm{S}$, equivalent to the $\mathrm{m}$ largest non-zero eigenvalues ë $1, \mathrm{e} 2, \ldots$ ëm. The data set's covariance matrix $\mathrm{S}$ can be found from:

$$
S=\frac{1}{n-1} \sum_{t=1}^{n}\left(x_{t}-\mu\right)\left(x_{t}-\mu\right)^{T}
$$

Where $\mu$ is the represent vector of $x$. The eigenvectors $e_{i}$ canpe found by solving The position of equations:

$\left(S-\lambda_{i} I\right) e_{i}=0$ for $i=1,2, \ldots \ldots . d \ldots$

(iii) conniving the eigenvectors, they are sorted by the scale of the related eigen values. Then the $m$ vectors with the major eigen values are chosen. The PCA projection matrix is then calculated as: $\quad W=E^{T}$-...- (iv)

Where, $E$ have the $\mathrm{m}$ eigenvectors.

Here $W$ is a $\mathrm{m} \mathrm{X} \mathrm{d} \mathrm{matrix.}$

The flowchart presentation the step by step method of conducting Principal component analysis is presented in Fig .1

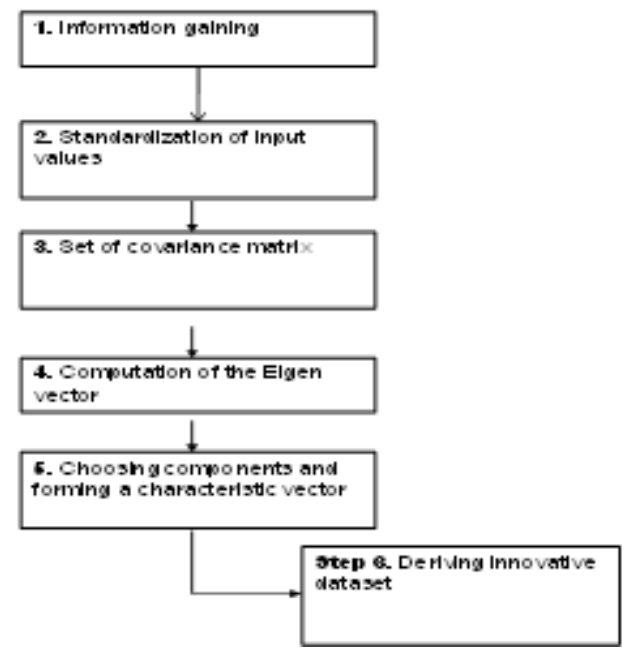

Fig 1: Flowchart presentation the step by step method of Principal component analysis
Where $e_{i}$ are the eigen values of $S$. After

\section{STUDY REGION}

The Gaddianaram region surroundings have been portrayed as the investigation region (Fig2). The examination territory contains twenty one wards. In light of the study, five noteworthy passages have been distinguished. The guide demonstrates the significant passages and real convergences in the assessment region. The guide appearing significant convergences can be seen in Fig 3

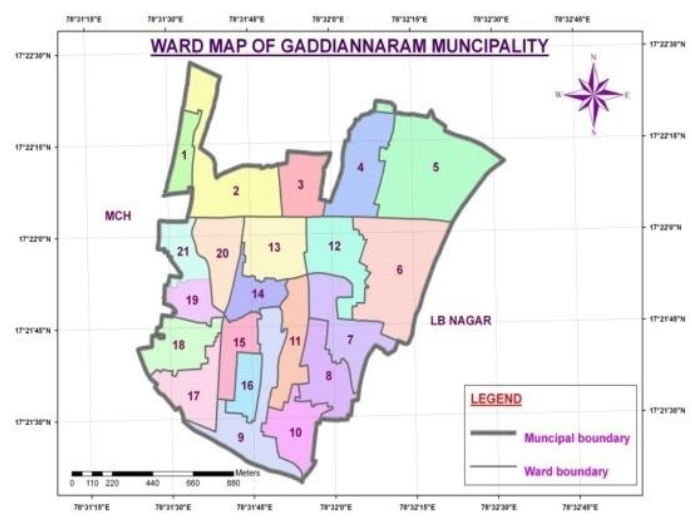

Fig .2

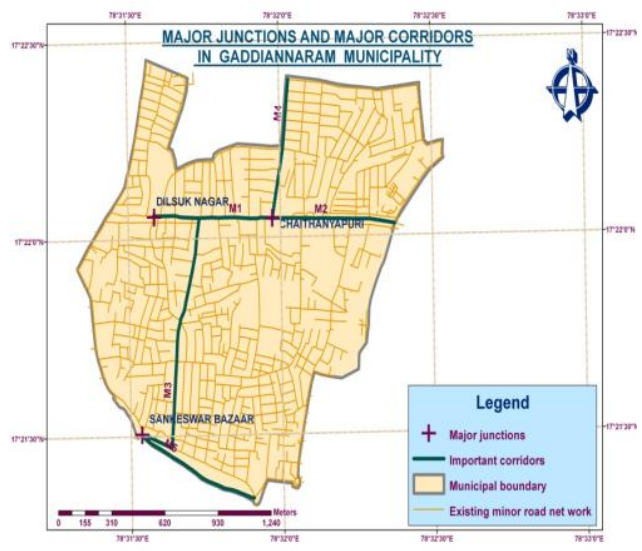

Fig.3

Information gathering and Processing

The field overviews that were done to gather the information in the investigation region have been assembled into two general classes. They are road categorize interpretation studies and traffic interpretation examines. The information gathered from these overviews has been investigated to assess the system attributes of the assessment region.

The contributor are categorized in four groups -- Geometric attributes, traffic characteristics, land usage or road side features and Utility attributes. The attributes considered under each version are according to the next.

A. Geometric qualities

Geometric qualities speak to the geometric highlights of the roadway influencing the Level of administration of the connection. These are the static qualities of the street foundation.

They are: 
1) Roadway width in meters (RW1)

2) Carriageway width in meters (CW1)

3) Stopping sight separate in meters (SSD1)

4) Number of bends on the connection (NC1)|

5) Pavement Condition record decided from the rating of the asphalt in light of the asphalt condition and riding solace experienced by the client to the size of 1 to 5,5 being a superb asphalt and 0 being a blocked asphalt.

- (PCI1)

6) Number of passageways on the connection (NA1)

B. Traffic qualities: Traffic qualities are the dynamic attributes of the street that impact the dimension of administration of the connection. They are

1) Headway in a moment or two (H1)

2) $V / C$ Ratio (VCR1)

3) Speed in kmph (V1)

4) Delay in a moment or two (D1)

C. Land use or Road side Characteristics: These are additionally the static components of the connection which impact the operational proficiency of the connection. They are:

1) Commercial territory along the street side of the connection in sq . km (CA1)

2) Residential territory along the street side of the connection in sq $\mathrm{km}$ (RA1)

3) Semi Residential zone along the street side of the connection in sq $\mathrm{km}$ (SRA1)

4) Industrial region along the street side of the connection in sq . $\mathrm{km}$ (IA1)

5) Intensity Parking, business exercises and street side exercises in a point scale (PBE1 showing stopping, business exercises and infringements)

D. Utility qualities: Utility qualities are the attributes of the connection demonstrating the level of utility of the connection with reference to the static examination and dynamic examination.
Analysis of contributors

Step $i$ : Establish the scope over which the connection is to be evaluated (i.e., place the superior limits of this examination scale) also assign a value of 0.0 to 1.0 to those end points, so in this order. Since the goal meaning is maximization, the maximum value from the range is that the connection that has the enhanced fundamentals of hazard creation. In the example of minimization, the very least significance in the variety will be assigned to value of 1.0 whereas maximum value is assigned a meaning of 0 . The objective function is optimized to spot the connections in the system that are contributing to congestion as well as the aspects that are liable for congestion at the system analysis criteria for describing the purpose function would be the route attributes that affect more in associated with this congestion or threat occurrence. A direct result is identification of operational features is obtained in (Nesamani K.S. etal 2005) and also Stephen r. Alderson \& Yorgsos Stepharedes 1986 which assesses the hyperlinks dependent on the geometrics, traffic, land usage and usefulness characteristics and demonstrated as trong impact on the total operation of the network. The principal criterions using their goal functions that offer perfect worth for congestion are connected below.

Step-ii: Computation of this covariance matrix: how covariance of this past matrix will be originate employing the software MATLAB.

Step-iii: Computation of the eigenvectors and eigen value.

Step-iv: Computation of the Principal components

Step-v: Deriving innovative Dataset

The last values are accessed by breeding of this sole transposed matrix i.e. main elements matrix along with uniform matrix. The last values obtained will be the constant values.

Step-vi: Finding the blocking associations: From innovative data set the concluding values of speed are compared with actual values. Therefore the congestion generated in links is found out. 


\section{Finding Clog Models for the Urban Traffic Blocking \& Assessment of Corridors}

\section{CONCLUSION}

With speed as main criterion, it is revealed that the risk is produced in the links and isolated in the related demand

S.No . Connection id Name of Link id

1) M3 Dilsukhnagar - SK market

2) M5 SK market - Saroorstreet

3) M1 Dilsukhnagar - Chpuri

The accompanying measures are proposed so as to control the vulnerability age delivered on the significant passages of the assessment region dependent on the three paradigms speed, deferral and progress.

1) Promotion of land utilize must be debilitated along the passages.

2) Speed inspection procedures are to be taken consideration.

3) Parking, stacking and emptying exercises are limited and directed all through the halls

4) Raised footways, obstructions and foot over scaffolds are prescribed to debilitate the walkers preceding onward the fundamental halls.

5) Road delineators are suggested along the path markings.

6) Face-lifting of the intersections is suggested.

\section{EFERENCES}

1. Dr Awari Mahesh Babu, Study of Metropolitan Transportation in Major Cities in India Advances in Computational Sciences and Technology ISSN 0973-6107 Vol 10, No 4 (2017)

2. Chu, N. H., \& Nguyen, V. D. (2018). The Multi-Response Optimization of Machining Parameters in the Ultrasonic Assisted Deep-Hole Drilling Using Grey-Based Taguchi Method. Int. J. Mech. Prod. Eng. Res. Dev, 8, 417-426.

3. Jolliffe I.T, "Principala Component analysisa", second edition

4. Jonathon Shlens, "A Tutoriala on PCA", Center for Neural Science, New York University, CA

5. Taufik, A., Okamoto, S., \& Lee, J. H. (2015). Multi-Rotor Drone to Fly Autonomously along a River Using a Single-Lens Camera and Image Processing. International Journal of Mechanical Engineering, 4(6), 39-49.

6. Ack Malczeski, 1998, "GIS and Multi-criteria assessment study", Edition 1 .

7. Zabbar, M. A. B., \& Ahmed, C. N. (2016). Design \& Implementation of an Unmanned Ground Vehicle (UGV) Surveillance Robot. International Journal of Electrical and Electronics Engineering (IJEEE), 5(6), 2278-9944.

8. Bruno Santos, 24-02-2009, “A aMulti-objective Approacha to Long-term Inter urban Multi-levela Road ", Journal of Transportation Engineering.

9. DAS, S. P., Bhatt, D., \& Path, S. (2017). Transformation Of Urban Transportation-Strategic Perspective A Case Of Uber Technologies, Inc. International, Journal of Research in Business Management, 5(3), 69-78.

10. Albert John Mallinckrodta, 8-8 2009 ,"VCI, a regional volume/cim of urban congestiona", ASCE journal of Transportation Engineering,

11. Tanveer, S. (2016). Application of Graph Theory in Representing and Modelling Traffic Control Problems. International Journal of Mathematics and Computer Applications Research (IJMCAR) ISSN (P), 2249-6955.

12. A.Garib, A.E.Radwan and H.Al-Deek," Estimatinga magnitudea and Duration of indent delays ".SCE
Table 1: Link Input attributes of the characteristics in each

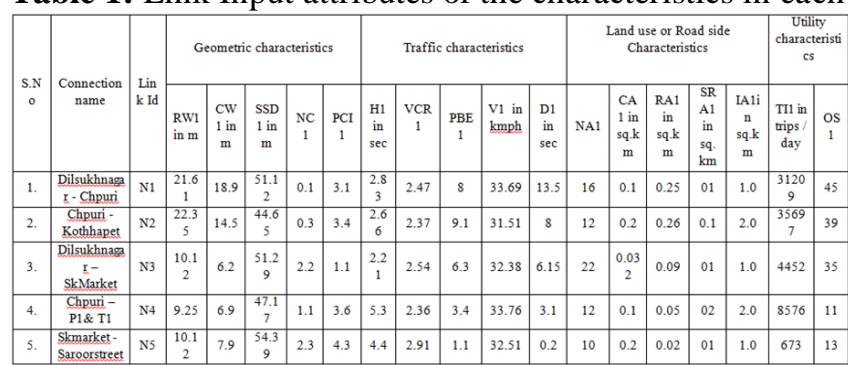

\section{Speed possibility investigation}

If expected assessment of speed of the connection is smaller number than inventive key value, possibility determination be create at the knob. Therefore threat main concern relations are allocated as follow

Table 2

\begin{tabular}{|c|c|c|c|c|c|c|}
\hline S.No & $\begin{array}{c}\text { Connection } \\
\text { name }\end{array}$ & Connection & $\begin{array}{c}\text { Speed } \\
\text { following } \\
\text { investigation }\end{array}$ & $\begin{array}{c}\text { Original } \\
\text { Speed }\end{array}$ & Variation & $\begin{array}{c}\text { Hazard } \\
\text { main } \\
\text { concem }\end{array}$ \\
\hline 1 & $\begin{array}{c}\text { Dilsukhnagar } \\
\text { - Chpuri }\end{array}$ & $\mathrm{N} 1$ & 31.00684 & 31.59 & -0.58 & 3 \\
\hline 2 & $\begin{array}{c}\text { Chpuri }- \\
\text { Kothhapet }\end{array}$ & $\mathrm{N} 2$ & 32.54173 & 29.6 & 2.94 & 0 \\
\hline 3 & $\begin{array}{c}\text { Dilsukhnagar } \\
- \text { Skmarket }\end{array}$ & $\mathrm{N} 3$ & 31.36854 & 32.28 & -0.91 & 2 \\
\hline 4 & $\begin{array}{c}\text { Chpuri }- \\
\text { P1\& T1 }\end{array}$ & $\mathrm{N} 4$ & 31.31442 & 30.56 & 0.75 & 0 \\
\hline 5 & $\begin{array}{c}\text { Skmarket- } \\
\text { Saroorstreey }\end{array}$ & $\mathrm{N} 5$ & 27.00714 & 33.61 & -6.60 & 1 \\
\hline
\end{tabular}

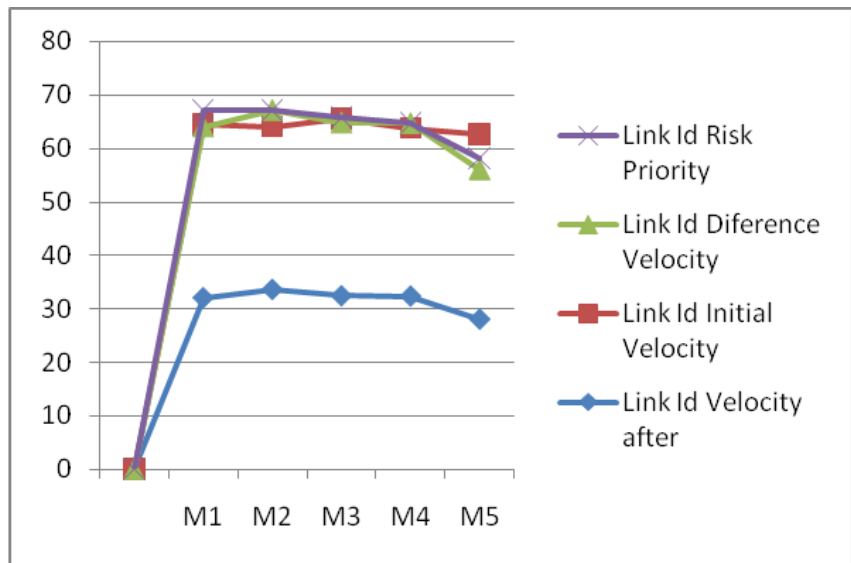

Fig.4 Possibility main concern graphs for speed measure 